\title{
A Comparative Study Of Certification Systems Based On Ethical Codes Of Medical Information On The Internet
}

\author{
Asae Ueda, Waseda University, Japan \\ Akiko Eura, Waseda University, Japan \\ Manabu Yamaji, Waseda University, Japan \\ Hiroaki Mitani, Japan Medical Information Association, Japan \\ Atsushi Ogihara, Waseda University, Japan
}

\begin{abstract}
Access to medical information has increased all over the world with the increase in Internet usage. Therefore, it is imperative to ensure the quality of medical information on the Internet. In this study, nine organizations having ethical codes relating to medical information on the Internet were subjects. Of these, ethical codes were compared on the basis of form and content. The certification systems were compared on the basis of number of certified websites, number of certified countries, cost to certify, process of certification and term of certification. As this result, here were only a few differences in form although each ethical code emphasized different content. It is unclear which certification system was the best, as all had advantages and disadvantages. The promotion of a certification system needs support from governments or other organizations. In conclusion, we propose three steps to ensure quality and control medical information online: (1) update the ethical code at least annually, (2) work with other organizations to enforce ethical codes and certification systems, and (3) raise awareness of these approaches.
\end{abstract}

Keywords: Ethical code; Certification system; Medical Information; Internet

\section{INTRODUCTION}

1 n recent years, information and communication technologies have shown remarkable development worldwide. According to a 2011 white paper on telecommunications, supported by a study grant from Japan's Ministry of Internal Affairs and Communications, the number of Internet users in Japan was over 94.0 million at a utilization rate of 78.2\% [1]. Internet World Stats reported that this number accounted for about 5\% of worldwide Internet users in 2011 [2]. The increasing availability of information has directly benefited many aspects of people's daily lives.

As in other fields, the Internet is widely used to seek information on illness, wellness, and medical care and for Internet healthcare services. Given that the Internet traverses geographical and temporal limits, it might create avenues for in the future [3]. It has changed the method of gathering medical information for a large number of people.

A recent study showed that the Internet is an effective tool for gathering medical information for people. For instance, in September 2007, Takahashi et al. conducted a cross-sectional survey of a quasi-representative sample $(\mathrm{N}=1,200)$ of the Japanese general population aged $15-79$ years. They reveal that the Japanese moderately used the Internet on personal computers for health purposes [4]. In another instance, in December 2008, the Pew Research Center's Internet \& American Life Project started conducting ongoing surveys on a sample $(\mathrm{N}=2,258)$ on the social impact of the Internet, including its effect on health and healthcare. The survey confirms the wellestablished finding that 8 in 10 Internet users, or $61 \%$ U.S. adults, have searched on the Internet for health information [5]. 
Access to medical information via the Internet has transformed the relationship between patients and physicians, and the process of medical treatment is changing from one where the physician authoritatively gives advice and treatment to one where there is shared decision-making between the physician and patient. The factors contributing to these changes include a reduction in the asymmetry of information between them, the increasingly prevalent concept of the e-consumer, and lessening of the perception that patients lack information. Nowadays, "econsumer" has become a commonly used word in Japan [6].

As an increasing number of people access medical information on the Internet, concerns on the quality of medical information available to consumers has been rising. The general public has come to adopt a critical view of misinformation as it can lead to life-threatening conditions [7]. Problems have been cited in Europe and the United States, as well as in Japan, about the quality of medical information on the Internet [8], [9]. Recent studies have suggested that further research is needed to prevent these problems. A RAND Corporation study, on behalf of the California Health Care Foundation (CHCF) [10], reported that a large amount of medical information on the Internet has serious problems and can be harmful. After this study, numerous surveys and studies have painted a picture of dubious information, widespread practice of fraud, potentially dangerous claims, and the risk of exposing people to harm [7]. Even when information appears to be of high quality, it can cause harm to people unintentionally [11]. There are various factors that cause harm: language and complexity barriers [12]; inappropriate audience or context; unavailability of certain services or products in different parts of the world; difficulty in interpreting scientific data; accuracy and currency of information; and potential for source bias, source distortion, and self-serving information [13].

In this study, we propose ethical codes and certification systems for ensuring the quality of medical information on the Internet.

Ethical codes are based on self-regulation by organizations that provide information and services, and are developed so that consumers can safely use medical information [14]. It aims to ensure the quality of medical information in Europe and North America. Various ethical codes such as the e-Health Code of Ethics, Health on the Net Foundation (HON Foundation), Hi-Ethics, and Health Insurance Portability and Accountability Act (HIPAA) were created as the Internet was developing. They assure the safety and benefit of consumers when medical information and services are provided by companies or individuals [6].

Certification systems are one of the most important tools to control the quality of medical information on the Internet. Monitoring of ethical codes by third-party organizations protects consumers from harmful information and protects personal data. Demand for certification systems has been increasing in order to filter harmful medical information and to positively identify and select high-quality medical information. These systems also encourage providers to follow the best practices of ethical codes and encourage medical societies to develop quality criteria for consumer information [15].

In Japan, the Ministry of Health and Welfare has set up an investigative commission to address the quality of medical information on the Internet. The commission proposed three policies to ensure quality: the creation of an ethical code for the content and investment criteria for websites, the implementation of a certification system to determine whether content complies with the ethical code, and the establishment of a counseling service for patients and medical organizations [16]. Complying with these policies, some organizations have established an ethical code and certification system to ensure quality of medical information in Japan.

An increasing number of people now want to access overseas information, which exposes them to various crossborder information breaches, such as access to inappropriate information and theft of personal data. Therefore, it may be necessary to address this situation by establishing of a unified ethical code and certification systems. However, to our knowledge, there are no recent studies that compare these approaches from foreign countries as well as Japan. Thus, this study aims to conduct a comparative review of approaches between them. 


\section{OBJECTIVE}

Various organizations have developed quality ethical codes for medical-related websites. Some of these organizations require verification to prove compliance with their ethical codes, while others are completely voluntary. This article, which uses data from previous studies and reports from CHCF, considers the self-certifying standards developed by Japan, the United States, and Europe. We compared nine sets of organizations related to medical information websites [14], [17].

\section{2-1. Outline of third-party organizations}

General information about the launch, location, and mission of the nine organizations is given below.

\section{Japan Medical Association (JMA)}

The JMA is the national body of Japanese physicians. There are approximately 165,000 members. Launch: 1916. Based: Japan. Mission: To provide leadership for physicians and to promote the highest standards of medical ethics and education to protect the health of all Japanese citizens [18].

\section{Japan Internet Medical Association (JIMA)}

JIMA is a voluntary association comprising doctors, patients, citizens, and advocates. JIMA protects both users and providers of health websites. For users, JIMA details guidelines on using medical information, while for providers, it proposes ethical codes, certification seals, and implements reviews and certifications. Launch: 1998. Based: Japan. Mission: To contribute to the enhancement of public benefit by promoting a safe and productive environment that can be used by patients and citizens to access high-quality medical information on the Internet [19].

\section{American Medical Association (AMA)}

AMA revolutionized medicine in the United States. Launch: 1847. Based: the United States. Mission: To promote the art and science of medicine and the betterment of public health [20].

\section{Internet Health Coalition (eHealth)}

eHealth was founded as a nonprofit organization. It aims to achieve its mission through consumer and provider education; self-regulation; and the nurturing of Internet communities that promote ethical, innovative, and high-quality medical information and services [10]. Launch: 1997. Based: the United States. Mission: To improve the quality of medical resources on the Internet.

\section{Health Internet Ethics (Hi-Ethics)}

Hi-Ethics was incorporated as a nonprofit organization to guide information providers and to promote consumption of the most widely used US-based consumer health Internet sites [21]. Launch: 2000. Based: the United States. Mission: To assure consumers who use health websites on the Internet.

\section{Utilization Review Certification Commission (URAC)}

URAC is a nonprofit organization found to promote healthcare quality through its accreditation, education, and measurement programs [7]. Launch: 1990. Based: the United States. Mission: To promote continuous improvement in the quality and efficiency of healthcare management through processes of accreditation and education [7]. 


\section{Health On the Net Foundation (HON Foundation)}

The HON Foundation is a nonprofit organization founded by the state of Geneva and the Geneva Ministry of Health. It offers ethical codes for health information providers on the Internet, certification seal, and a wide variety of Internet tools. Launch: 1995. Based: Switzerland. Mission: To promote and guide the development of useful and reliable Internet health information and it's appropriate and efficient use [22].

\section{MedCERTAIN}

MedCERTAIN was founded under the EU Action Plan for safer use of the Internet [23]. Launch: 2000. Based: European countries. Mission: To establish trust and improve the quality of health information on the Internet by the "four E's": Educating the public; encouraging self-governance, for example, encouraging health information providers to conform to ethical codes for health and promoting self-labeling; evaluating information measurement and certification of information; and enforcement [13].

\section{European Commission}

The European Commission was founded as the EU's executive body and represents the interests of Europe as a whole. Launch: 1946. Based: European countries. Mission: To protect world peace and promote economic and social progress [24].

\section{2-2. Outline of ethical codes}

The outline, launch, objective, and target users of the nine ethical codes are given below.

\section{Guidelines for Medical Facility Sites on the Internet (JMA)}

Guidelines for Medical Facility Sites on the Internet have established in order to provide medical information. Launch: 2005, revised in 2008. Objective: Members of JMA. Target users: Maintain trust in the medical service community by proving proper medical information on the Internet.

\section{eHealth Code of Ethics 2.0 (JIMA)}

The e-Health Code of Ethics is a voluntarily adopted set of standards around the use of information technology in healthcare, which has been established to protect important personal information while ensuring quality of information and services provided [25]. Launch: 2003. Objective: To protect important personal information (privacy), while ensuring quality of information and services provided [11]. Target users: The e-Health Code of Ethics may be applied to institutions, corporations, organizations, networks, other groups, and individuals that provide healthcare information and services on the Internet [25].

\section{Principles Governing AMA Web Sites (AMA)}

The principles Governing AMA Web Sites was established to review the existing individual ethical codes and to draft a single document that would provide principles to govern the presentation and functionality of the four major areas for which quality standards were needed: content, advertising and sponsorship, privacy and confidentiality, and e-commerce [20]. Launch: 2000. Objectives: To govern the AMA websites and publications. Target user: AMA websites and other providers and users of medical information on the Internet [11].

\section{eHealth Code of Ethics (eHealth)}

The eHealth Code of Ethics was established for medical-related websites and comprises eight principles of ethical codes, which each medical organization can interpret according to its unique needs [10]. Launch date: 2000. Objectives: To (1) protect from harm, (2) create an ethical environment, and (3) ensure synergy among the various entities. Target users: It developed as a set of guiding principles aimed at health Internet stakeholders worldwide. 
These stakeholders include health-application developers, site sponsors, managers, webmasters, clinicians, laypeople who seek health information, products, and services via the Internet, policymakers, academics, and publishers [11].

\section{Hi-Ethics Principles (Hi-Ethics)}

The Hi-Ethics Principles were established to offer Internet-based health services to consumers. Launch: 2000. Objective: To (1) provide Internet health services that reflect high quality and ethical standards, (2) provide health information that is trustworthy and up-to-date, (3) clearly identify Internet advertising and disclosing sponsorships or other financial relationship that significantly affect our content or services, (4) keep personal information private and secure, and employ special precautions for any personal health information, and (5) empower consumers to distinguish Internet health services that follow our principles from those that do not. Target users: US-based commercial websites that offer or plan to offer health services, products, and information to consumers [11].

\section{URAC Accreditation Guide, Version 3.0 (URAC)}

The URAC Accreditation Guide, Version 3.0, has established ethical codes of 33 programs, covering not only health but also case management and claims processing. More recently, URAC has been developing a program for the accreditation of health-related websites [6]. Launch: 2001. Objectives: (1) To address the concerns of consumers and other healthcare stakeholders and (2) to provide a tool to identify websites that meets high standards for quality and accountability. Target users: health-related websites, initially those organizations providing managed care services [11].

\section{The Code of Establish for Health Websites (HONcode)}

The Code of Establish for Health Websites (HONcode) is the oldest and most widely endorsed set of ethical codes for health website developers. Launch: 1996. Objectives: To guide laypersons and medical practitioners to useful and reliable Internet medical and health information. Target users: Health-information providers, consumers, and medical practitioners [11].

\section{A Code of Ethics for Health Care on the Internet (MedCERTAIN)}

A Code of Ethics for Health Care on the Internet is an international trustmark for health information that enables consumers to filter harmful information and to identify and select high-quality information [13] Launch: 2000.Objectives: (1) To establish self and third-party organization rating systems that enable consumers to filter harmful health information and to identify and select high-quality information through website content labels, (2) to create of an enforcement infrastructure, (3) to ensure consumer education, (4) to actively encourage information providers to conform to ethical codes of conduct and (5) to support information providers and rating facilities achieve information through the application of meta tags and labeling technologies. Target users: Information providers and rating organizations, and the end users of health information [11].

\section{eEurope 2002: Quality Criteria for Health Related Websites (European Commission)}

eEurope 2002: Quality Criteria for Health Related Websites was established to develop ethical codes on quality criteria for health-related websites. The aim of this directive was to draw up a commonly agreed set of simple quality criteria that member states, as well as public and private bodies, may converge refer to develop quality initiatives for health-related websites [24]. Launch: 2002. Objectives: To produce a European Commission and good practice ethical codes for health information on the Internet. The scope of this communication will be to cover health-related information and services on the Internet. Target users: European Union member states [11].

\section{2-3. Outline of certification systems}

Certification systems are currently offered by only three of the abovementioned organizations: JIMA, URAC, and HON Foundation. The outlines, formulation process and criteria, and revisions are as follows: 


\section{JIMA}

The JIMA certification system was fully implemented in 2002. The JIMA trustmark displayed on the websites of JIMA members indicates the site operators' adherence to JIMA's ethical codes. It also signifies that users are able to express dissatisfaction with opinions on about the information or service provided via a feedback system to the site administrators [6].

\section{URAC}

The URAC certification system was fully implemented in 2001. It has over 30 certification programs and offers a wide range of quality benchmarking programs and services that keep pace with the rapid changes in the healthcare sector [25]. In this study, we evaluate the Health Web Site and Health Content Vendor Accreditation Program.

\section{HON Foundation}

The HON Foundation's certification was fully implemented in 1996 and is the oldest certification system [22]. It is an ethical standard that aims to offer quality health information and demonstrates the intent of a website to publish information transparently. The transparency of the website will improve the usefulness and objectivity of the information and the publication of correct data [9].

\section{METHODOLOGIES}

In May 1-7, 2011, searches were conducted on medical websites to identify their objectives with the aim of evaluating the ethical codes and certification systems.

\section{3-1. Ethical code}

The evaluation of ethical codes consists of evaluating the form and content of ethical codes. First, the evaluation accounts for the number of categories, items, and features. Second, the content is compared on six categories: basic information, content, advertisement and sponsor, data protection, accountability, and accessibility. Each category consists of 5-10 items and is compared using examples from previous studies report for the presence of each category in the ethical codes. The numbers within parentheses indicate the number of items in each category.

\section{3-2. Certification system}

The certification systems are compared on the basis of five categories: number of certified websites, number of certified countries, cost to certify, process of certification and term of certification. Examples from previous studies [13] were used as a reference.

\section{RESULTS}

\section{4-1. Evaluation of the ethical codes}

\section{4-1-1. Evaluation of forms}

As shown in Table 1, there were no substantial differences among the forms of the nine sets of ethical codes.

\section{Number of categories}

The ethical code with the most categories was Hi-Ethics (14 categories), and that with the least categories was AMA (4 categories). 
Table 1. Summary of forms for each ethical code

\begin{tabular}{|l|c|c|l|}
\hline \multicolumn{1}{|c|}{ Objective } & Number of Categories & Number of items & \multicolumn{1}{c|}{ Feature } \\
\hline JMA & 5 & $1-11$ & Accompanying sheets \\
\hline JIMA & 7 & $1-21$ & Same definition on each item \\
\hline AMA & 4 & $1-15$ & Two ways of explanation \\
\hline eHealth & 8 & $3-14$ & Explanation with examples \\
\hline Hi-Ethics & 14 & $1-6$ & Definition list \\
\hline URAC & 8 & $2-12$ & Annotation on each item \\
\hline HONcode & 8 & 0 & Principle, Ethical code \\
\hline MedCERTAIN & 5 & $2-5$ & Simple explanation \\
\hline eEurope & 6 & $1-4$ & Simple explanation \\
\hline
\end{tabular}

\section{Number of items}

eHealth had the highest number of items (21 categories). Only MedCERTAIN did not separate categories into items with explanations. Among the other sets of ethical codes, there were many differences in the number of categories and items.

\section{Features}

With regard to the features of the forms, which typically contain many technical words, each ethical code was designed to make the content easier to understand.

\section{JMA}

There were 5 categories and 1-11 items on the Guidelines for Medical Facility Sites online. Features: The ethical code cited good and bad examples of controlling the content posted on websites and provided an accompanying sheet for personal information.

\section{JIMA}

There were 7 categories and 1-21 items on the eHealth Code of Ethics 2.0. Features: The ethical code had similar definitions for each category, including objectives, application considerations, and rules. It contained many items, but each was clear to understand.

\section{AMA}

There were 4 categories and 1-15 items on the Principles Governing AMA Web sites. Features: Some content was textual with long sentences, while some consisted of itemized explanations.

\section{eHealth}

There were 8 categories and 3-14 items on the eHealth Code of Ethics 2.0. Features: The ethical code featured an explanation with examples, an abstract, and a glossary of technical terms for each category. Each sentence was generally short.

\section{Hi-Ethics}

There were 14 categories and 1-6 items on the Hi-Ethics Principles. Features: The ethical code included a glossary of technical terms, which contained the highest number of items. 


\section{URAC}

There were 8 categories and 2-12 items on the Health Web Site Certification Guide, Version 3.0. Features: The ethical code had annotated explanations, points, and criteria for measurement. It contained the highest number of sentences.

\section{HONcode}

There were 8 categories but no items on the HONcode. Features: The ethical code uses collaborative websites to provide Social Network Services (SNS) and weblogs.

\section{MedCERTAIN}

There were 5 categories and 2-5 items on the Code of Ethics for Health Care on the Internet. Features: The ethical code had brief instructions and short sentences.

\section{eEurope}

There were 6 categories and 1-4 items on the eEurope 2002: Quality Criteria for Health Related Websites. Features: The ethical code had brief instructions for each category but detailed definitions for each item.

\section{4-1-2. Evaluation of content}

The results were compiled by category and ethical code (Table 2). In addition, the number of items was standardized to compare the content between ethical codes in Figure 1 (in such a way that it changed five to ten, if total number of item is five).

Category averages were as follows: Basic Information had 7.8 points, Information Content had 6.6 points, Data Protection had 6.4 points, Advertisements and Sponsors had 5.4 points, Accountability had 5.7 points, and Accessibility had 4.5 points.

\section{Basic Information}

This had the highest average across categories. Among the items, only Whereabouts (1-2), and Intended Audience (1-5) was not high enough to compare alongside the ethical codes.

\section{Information Contents}

The lowest scoring item was Author's Information (2-7); the highest scoring was Editorial Policy (2-4).

\section{Data Protection} 7).

The lowest scoring item was Notification of Modification (3-9); the highest scoring was Privacy Policy (3-

\section{Advertisement and Sponsor}

The lowest item was Sponsor's Proposal (2-6-2); the highest was Sponsor Policy (2-6-1).

\section{Accountability}

The lowest scoring items were Definition of Accountability (5-3), Attention (5-4), and Certification of Third-Party Organization (5-5), the highest scoring were Address to the Author (5-1) and Feedback (5-2). 


\section{Accessibility}

The lowest scoring items were Simplicity in Finding Information (6-1) and Acceptance of Cookie (6-5); the highest scoring was Simplicity of Information (6-2).

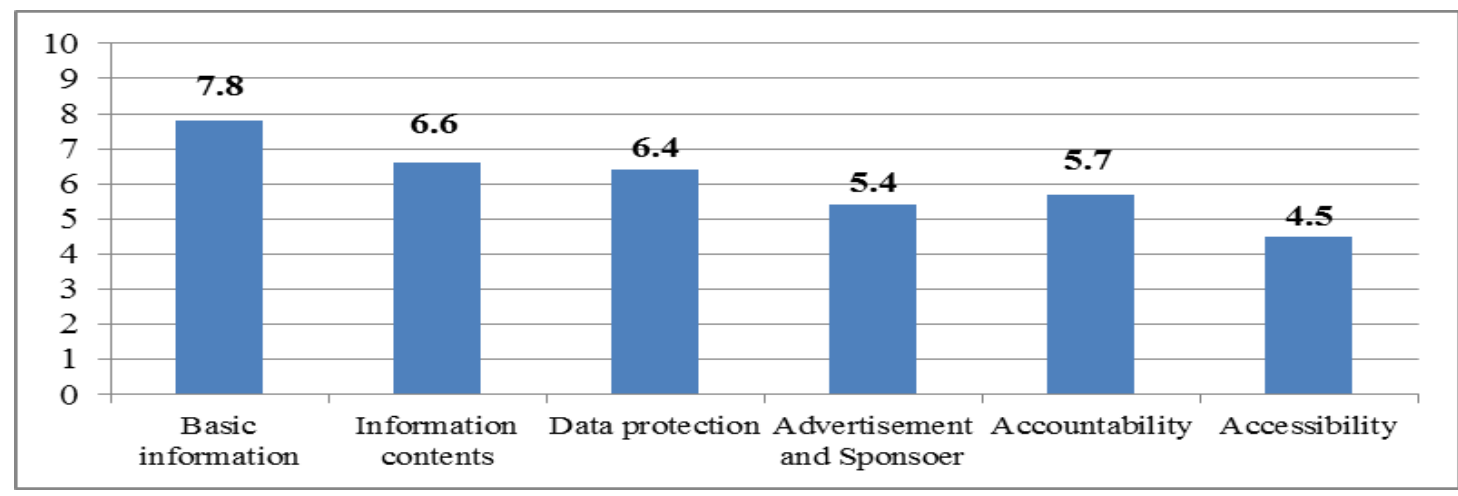

Figure 1. The average of the measured categories

The ethical codes were assessed against a maximum of 45. JMA acquired 26 points, JIMA 36, AMA 31, eHealth 32, Hi-Ethics 32, URAC 28, HONcode 28, MedCERTAIN 7, and eEurope 22 points. The result of ethical codes is shown in Table 2.

\section{JMA}

Guidelines for Medical Facility Sites on the Internet focuses on Basic Information, but the other categories are insufficient to refer to, particularly, Accountability.

\section{JIMA} Data Protection.

The eHealth Code of Ethics 2.0 includes all categories, with special attention to Information Content and AMA

Principles Governing AMA Web Sites focuses on Data Protection and the Advertisements and Sponsors gathered from the number of these items.

\section{eHealth}

The eHealth Code of Ethics focuses on Information Content and Data Protection.

\section{Hi-Ethics}

Hi-Ethics Principles focuses on Advertisements and Sponsors and Data Protection. However, the rest of the items have low scores, particularly, Accountability and Accessibility.

\section{URAC}

URAC Accreditation Guide, Version 3.0, focuses on Advertisements and Sponsors, Data Protection, and Accountability. The remaining categories have low scores. 


\section{HONcode}

HONcode focuses on Accessibility. In addition, it consists of fewer sentences compared with other ethical codes, but there are only a few differences in the number of categories.

Table 2. The feature of ethical codes by measurement items for each organization

\begin{tabular}{|c|c|c|c|c|c|c|c|c|c|c|c|}
\hline \multirow{5}{*}{$\begin{array}{l}\text { 1.Basic } \\
\text { Information } \\
\text { (5) }\end{array}$} & 1.1 & Does the site state organization name? & $\circ$ & 0 & 0 & 0 & 0 & & 0 & & 0 \\
\hline & 1.2 & Dose the site provide its Whereabouts? & $\circ$ & $\circ$ & & & & 0 & & & $\circ$ \\
\hline & 1.3 & Does the site indicate detail information of webmaster? & $\circ$ & $\circ$ & o & o & o & & 0 & & $\circ$ \\
\hline & 1.4 & Does the site state its objective? & $\circ$ & $\circ$ & $\circ$ & $\circ$ & $\circ$ & $\circ$ & $\circ$ & & $\circ$ \\
\hline & 1.5 & Does the site state its intended audience? & 0 & 0 & $\mathrm{o}$ & & & & $\mathrm{o}$ & & $\mathrm{o}$ \\
\hline \multirow{10}{*}{$\begin{array}{l}\text { 2.Advertisement } \\
\text { and Sponsor } \\
\text { (10) }\end{array}$} & 2.1 & Does the site display Advertising policy? & $\circ$ & $\circ$ & & 0 & $\circ$ & & & & \\
\hline & 2.2 & Does the site provide Advertising definition? & $\circ$ & $\circ$ & $\circ$ & o & $\circ$ & $\circ$ & $\circ$ & & \\
\hline & 2.3 & Does the site mention manifestation of advertisements? & & & $\circ$ & & $\circ$ & $\circ$ & $\circ$ & & \\
\hline & 2.4 & $\begin{array}{l}\text { Does the site indicated differences from the content to } \\
\text { advertisement? }\end{array}$ & & & $\circ$ & & $\circ$ & $\circ$ & $\circ$ & & \\
\hline & 2.5 & Does the site indicate relationship with advertisement? & 0 & & 0 & $\circ$ & 0 & 0 & $\circ$ & & \\
\hline & 2.6 .1 & Does the site provide Sponsor policy? & & 0 & 0 & 0 & 0 & 0 & $\mathrm{o}$ & 0 & 0 \\
\hline & 2.6 .2 & Dose the site describe the sponsor's purpose? & & & & & 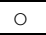 & & & & \\
\hline & 2.7 & Dose the site indicate relationship with sponsors? & & & $\circ$ & 0 & $\circ$ & $\circ$ & $\circ$ & & \\
\hline & 2.8 & $\begin{array}{l}\text { Does the site disclose sources of financing of the sponsoring } \\
\text { organization? }\end{array}$ & & $\circ$ & $\circ$ & $\circ$ & $\circ$ & & $\circ$ & & $\circ$ \\
\hline & 2.9 & Does the site provide a conflict of interest policy? & & & 0 & & $\circ$ & o & 0 & & \\
\hline \multirow{10}{*}{$\begin{array}{l}\text { 3.Information } \\
\text { Contents } \\
\text { (10) }\end{array}$} & 3.1 & Does the site provide Medical policy? & $\circ$ & $\circ$ & $\circ$ & $\circ$ & $\circ$ & $\circ$ & $\circ$ & & \\
\hline & 3.2 & Is the information/content clearly? & $\circ$ & $\circ$ & $\circ$ & $\circ$ & $\circ$ & & & $\circ$ & \\
\hline & 3.3 & Is the information/content detailed? & & $\circ$ & $\circ$ & 0 & $\circ$ & & $\circ$ & $\circ$ & \\
\hline & 3.4 & Does the site provide editorial policy? & 0 & $\circ$ & $\circ$ & $\circ$ & $\circ$ & $\circ$ & $\circ$ & $\circ$ & $\circ$ \\
\hline & 3.5 & Link to the source? & o & $\circ$ & & & $\circ$ & & & & $\circ$ \\
\hline & 3.6 .1 & Does the site provide reference definition? & $\circ$ & $\circ$ & 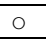 & 0 & & o & & & $\circ$ \\
\hline & 3.6 .2 & $\begin{array}{l}\text { Does the site indicate differences from the date the opinion to } \\
\text { report of fact? }\end{array}$ & $\circ$ & $\circ$ & ○ & $\circ$ & $\circ$ & $\circ$ & 0 & & $\circ$ \\
\hline & 3.7 & Does the site give the author's information? & & $\circ$ & & & $\circ$ & & & & \\
\hline & 3.8 & Does the site indicate when it was last updated? & $\circ$ & $\circ$ & $\circ$ & $\circ$ & $\circ$ & o & $\circ$ & & $\circ$ \\
\hline & 3.9 & Does the site provide foreign languages? & & $\mathrm{o}$ & & 0 & & & $\mathrm{o}$ & & $\mathrm{o}$ \\
\hline \multirow{10}{*}{$\begin{array}{l}\text { 4.Data } \\
\text { Protection } \\
(10)\end{array}$} & 4.1 & Does the site display its personal information policy? & $\circ$ & $\circ$ & $\circ$ & ○ & $\circ$ & $\circ$ & $\circ$ & & \\
\hline & 4.2 & Aim of use & $\circ$ & $\circ$ & 0 & 0 & $\circ$ & 0 & $\circ$ & & \\
\hline & 4.3 & Does the site indicate caretaker's information? & $\circ$ & $\circ$ & $\circ$ & $\circ$ & $\circ$ & $\circ$ & $\circ$ & & \\
\hline & 4.4 & Term of storage for data & & $\circ$ & & o & & o & & & \\
\hline & 4.5.1 & $\begin{array}{l}\text { Does the site mention acceptance/rejection of collecting } \\
\text { personal information? }\end{array}$ & $\circ$ & $\circ$ & $\circ$ & $\circ$ & $\circ$ & $\circ$ & & $\circ$ & $\circ$ \\
\hline & 4.5 .2 & Advantage/ Disadvantage of collecting personal information & & $\circ$ & $\circ$ & $\mathrm{O}$ & & $\circ$ & & & \\
\hline & 4.6 & $\begin{array}{l}\text { Does the site mention to share information with third } \\
\text { organization? }\end{array}$ & $\circ$ & $\circ$ & $\circ$ & 0 & $\circ$ & $\circ$ & $\circ$ & & \\
\hline & 4.7 & Does the site provide privacy policy? & $\circ$ & $\circ$ & $\circ$ & $\circ$ & $\circ$ & $\circ$ & $\circ$ & $\circ$ & $\circ$ \\
\hline & 4.8 & Regulation of use & & $\circ$ & & $\circ$ & $\circ$ & & $\circ$ & & \\
\hline & 4.9 & Notification of modification & & $\circ$ & & & $\circ$ & & & & \\
\hline \multirow{5}{*}{$\begin{array}{l}\text { 5.Accountability } \\
\text { (5) }\end{array}$} & 5.1 & Does the site contain address to the authors of the content? & $\circ$ & $\circ$ & $\circ$ & $\circ$ & & $\circ$ & $\circ$ & & $\circ$ \\
\hline & 5.2 & Does the site permit easy feedback from consumers? & & $\circ$ & $\circ$ & $\circ$ & $\circ$ & $\circ$ & $\circ$ & & $\circ$ \\
\hline & 5.3 & Accountability & & & & $\circ$ & $\circ$ & $\circ$ & & & $\circ$ \\
\hline & 5.4 & Attention & & $\circ$ & & & & o & 0 & 0 & \\
\hline & 5.5 & $\begin{array}{l}\text { Does the site display certification system from third } \\
\text { organization? }\end{array}$ & $\circ$ & $\circ$ & & $\circ$ & & & & & $\circ$ \\
\hline \multirow{5}{*}{$\begin{array}{l}\text { 6.Accessibility } \\
\text { (5) }\end{array}$} & 6.1 & Simplicity in finding information & & & & & & 0 & & & 0 \\
\hline & 6.2 & Simplicity of information & 0 & 0 & $\circ$ & 0 & 0 & $\circ$ & & & $\circ$ \\
\hline & 6.3 & Barrier-free & $\circ$ & $\circ$ & & $\circ$ & & & & & $\circ$ \\
\hline & 6.4 & Download ability & $\circ$ & $\circ$ & $\circ$ & & & & & & \\
\hline & 6.5 & Presence or absence of acceptance of cookies & & & $\circ$ & & & & $\circ$ & & \\
\hline \multicolumn{3}{|l|}{ Total scores } & 26 & 36 & 31 & 32 & 32 & 28 & 28 & 7 & 22 \\
\hline
\end{tabular}




\section{MedCERTAIN}

A CODE of Ethics for Health Care on the Internet focuses on keywords in all categories, not detailed content. There is no Accessibility content.

\section{eEurope}

eEurope 2002: Quality Criteria for Health Related Websites focuses on Basic Information and Accountability, but not on Advertisements and Sponsors or Data Protection.

\section{4-1-3. Measurement of certification system}

Given below is the result of the evaluation of these certification systems using five parameters: number of certified websites, number of certified countries, certification cost, process to certify, and certification term. The comparison of certification systems is shown in Table 3 .

Table 3. The comparison of certification systems

\begin{tabular}{|l|c|c|c|}
\hline \multicolumn{1}{|c|}{ Evaluation category } & JIMA & URAC & HONcode \\
\hline Number of certified websites & $\begin{array}{c}27 \\
\text { (Gold:14,Regular: 13) }\end{array}$ & 19 & 7,300 \\
\hline Number of certified countries & 1 & 2 & 102 \\
\hline Cost to certify & From free to about \$1,260 & $\begin{array}{c}\text { depended on the type of } \\
\text { certification program }\end{array}$ & Free \\
\hline Process of certification & 6 steps & 5 steps & 4 steps \\
\hline Term of certification & 6 weeks & 7 months & 8 months \\
\hline
\end{tabular}

\section{Number of certified websites}

The organization to certify the largest number of websites is HON Foundation, with over 7,300 certifications. Since August 1, 2010, JIMA's certifications have increased from one to two in order to promote certification systems, called "Gold mark (Traditional)" and "Regular mark (New)". Gold mark has certified 14 websites for non-profit organizations by charged and profit-oriented organizations and Regular mark has certified 13 for non-profit organizations by free.

\section{Number of certified countries}

JIMA has certified websites only in Japan; URAC, in the United States and Canada; and HON Foundation, in 102 countries.

\section{Cost to certify}

The summary of certification systems about JIMA is shown in Table 4.

Table 4. The summary of certification systems about JIMA

\begin{tabular}{|l|c|c|l|c|}
\hline \multicolumn{2}{|c|}{ A) For non-profit organization } & \multicolumn{2}{c|}{ B) For profit-oriented organization } \\
\hline Fee & (Gold) & (Regular) & Fee & (Gold) \\
\hline Application & $\$ 60$ & Free & Application & $\$ 126$ \\
\hline Review & $\$ 630$ & Free & Review & $\$ 1,260$ \\
\hline Charge of Use & $\$ 60$ & Free & Charge of Use & $\$ 126$ \\
\hline
\end{tabular}

As URAC has various programs, it is unclear whether JIMA or URAC is more expensive. However, JIMA's Regular certification is free. 
The two of certification whish are HON Foundation and the Regular types by JIMA are free. However, the Gold type of JIMA and URAC are not free. As for URAC, the cost depended on the type of certification program. URAC's charges include the certification itself and charges for an onsite visit to the website by one or more certification reviewers.

JIMA has launched new certification systems that is free of charge. The certification system has changed since August 1, 2010, from one mark to double marks such as Gold mark for nonprofit organizations and profitoriented organizations and Regular mark for nonprofit organizations.

\section{Process of certification}

While there are a varying number of steps, there are not many differences in the certification processes. The steps follow each other, and health information providers must go through a step-1 certification process to be evaluated further. In addition, the certification carries a trustmark such as a logo or seal for each step. The JIMA certification process includes six steps; URAC, five steps; and HON Foundation, four steps. All certification systems had the same processes, such as Application and Reviews by organizations [26], [27], [28].

\section{JIMA}

Step-1 (Application): Submit application on JIMA website to use its trustmark.

Step-2 (Self-assessment): Complete a self-assessment and send it as an attachment.

Step-3 (Payment-Gold type): On acceptance by JIMA, payment is required only for the Gold type.

Step-4 (Review by JIMA): Pre-review conducted by organizers, followed by a reviewed by committees (term of certification: 1-2 weeks for Regular type, 4-8 weeks for Gold type).

Step-5 (Notice of result): The website receives evaluation results and a tag is issued for displaying the trustmark.

Step-6 (Verification): Check if the website is displaying the mark.

\section{URAC}

Step-1 (Application): To request the organization to provide the ethical codes for the certification program and undergo a self-assessment.

Step-2 (Payment): Apply operating policies and procedures to ensure compliance with the ethical codes.

Step-3 (Official Application): Submit the application and then seek a review.

Step-4 (Review by URAC): Committee evaluates the website as per URAC Accreditation Guide, Version 3.0.

Step-5 (Notice of result): After review by committees, the certification is issued.

HON Foundation

Step-1 (Application): Read the HON Foundation application policies and submit the application form to inform HON Foundation about the website.

Step-2 (Evaluation): A reviewer evaluates the website and assesses conformity with HON Foundation; the website receives the result of the evaluation via e-mail.

Step-3 (Modification): If necessary, make the required modifications and inform HON Foundation. The reviewer revaluates the website considering the last modifications made on the website.

Step-4 (Certification): Award of certification and display of the HON Foundation's seal and associated text on the website linked to the certification.

\section{Term of certification}

JIMA provides certifications medical-related websites for six weeks, URAC provides certifications for seven months, and HON Foundation provides certifications for eight months. 


\section{DISCUSSION}

\section{5-1. Ethical code}

The different ethical codes were similar, although there were slight differences in the number of categories and items. However, considering this result in relation to the content of the ethical codes, those categorized in more detail tended to be more extensive, with the exception of the AMA, which uses four categories but contains a lot of content.

With regard to the features of the form, as the ethical codes contain a large number of technical words, each ethical code was designed to clarify its content. For example, the eHealth Code of Ethics contained explanations with examples, an abstract, and a glossary of technical terms for each category. These approaches make medical information and service-related websites easily comprehensible to consumers. However, any information provided only by itemization is difficult to understand. Therefore, this study recommends that providing information in brief sentences and generating additional ideas to supplement as necessary (such as the style followed by the eHealth Code of Ethics and HONcode) make it easier to understand the ethical code in its entirety.

Regarding the evaluation of content, Site Objective (1-4) and Editorial Policy (2-4) were mentioned the most in the ethical codes. This suggests that these items may be vital to website use and control. In spite of variations in regulations by country, many ethical codes emphasize compliance with regulations in dealing with medical and personal information. Therefore, the discussion must include regulation, particularly since the collection of personal information can have a negative impact on consumers using ethical codes that do not mention these areas, such as MedCERTAIN and eEurope.

There are many important items not mentioned by most of the ethical codes, most notably Intended Audience (1-5) and Foreign Languages (2-9). Therefore, the objectives of the websites need to be communicated in an easily understandable manner. This is also needed because of the increasing access to websites from foreign countries. Thus, it is no longer sufficient for websites and their ethical codes to be maintained only for local consumers.

To formulate a good ethical code, organizations must cooperate with each other, such as Hi-Ethics and URAC do [29]. For content, the relationship between two organizations is based on close interaction. In addition, they try to cooperate and fill the gap between two ethical codes. It is likely that this relationship will be more important towards development efforts.

\section{5-2. Certification systems}

There are some differences in the points awarded for certified marks and fees. HON Foundation has the highest number of certified marks. This is probably because HON Foundation has been using the oldest ethical code, which has been translated into 35 foreign languages (Arabic, Catalan, Chinese, Czech, Danish, Dutch, English, Finnish, French, German, Greek, Hungarian, Icelandic, Italian, Japanese, Korean, Macedonian, Malaysian, Norwegian, Polish, Portuguese, Russian, Slovak, Spanish, Swedish, and Turkish, e.g.) [30], and because certification is free. However, it has been postulated that there are 30 members responsible for certifying about 300 websites per month. Thus, it is unclear how many of the several thousand sites, have actually implemented the ethical codes. These are the cons of HON Foundation, although its certification has received wide recognition worldwide.

These results suggest that ensuring the appropriate function of websites requires controlling the quality of their certification systems. This is facilitated through third-party cooperation.

It is therefore clear that an appropriately practiced certification system is one of the most important tools in controlling the quality of medical information on the Internet. However, JIMA has only certified 27 medical websites. Furthermore, there is concern about the use of personal information among company employees and consumers, and it has been pointed out that measures to address this issue in Japan have been slow in coming. To 
ensure high quality medical information on the Internet, an important goal is to gain recognition and increase the websites via certification marks and controlled applicable feedback systems. Compared with overseas ethical codes, Japanese certification marks are few because of the high cost of certification. However, the cause of this certification gap is yet to be verified scientifically.

\section{5-3. Conclusion}

In view of the rapid proliferation of medical information on the Internet, it is often difficult for consumers to identify websites that offer useful and reliable medical information [22].

In this study, we discussed the current quality of medical information on the Internet and its growing prevalence. There are only a few differences between ethical codes in terms of form and content, although different ethical codes emphasize different categories or items. The results of this study show that ethical code creators should share ethical code content to improve the medical field.

Nowadays, it is easy to collect medical information through the Internet. Thus, medical information can have a direct impact on the user's health and wellbeing. Therefore, it becomes essential to standardize the available medical information by applying ethical codes and clearly indicate all websites that comply with those codes [31].

Moreover, it is necessary to update ethical codes when the laws relating to medical information are revised. Thus, we need to perform a major revision of the text completely revise the structure and arrangement of articles, add areas to address new services available from medical institutions, and include examples of relevant government guidelines and laws [32].

Thus, we propose three steps to ensure and control the medical information on the Internet: (1) update the ethical code at least once a year (2) work with other organizations to enforce ethical codes and certification systems and (3) raise the awareness of ethical codes and certification systems.

Future studies must evaluate other ethical codes and certification systems that have not been examined in this study. Further, evaluation items need to improve more in order to evaluate medical-related websites.

\section{AUTHOR INFORMATION}

Asae Ueda is a graduate student of Department of Health Sciences and Social Welfare, Graduate School of Human Sciences at Waseda University. E-mail: uedaasae0314@ hotmail.co.jp

Akiko Eura was an undergraduate student of Department of Health Sciences and Social Welfare at Waseda University. E-mail: a_eura02@yahoo.co.jp

Manabu Yamaji is a researcher in Advanced Research Center for Human Sciences at Waseda University, Japan. His current research and teaching interests are in the general area of quality management. E-mail: manabu.yamaji@gmail.com

Hiroaki Mitani is a bureau chief of Japan Medical Information Association (JIMA), Japan. E-mail: mitani2@gmail.com

Atsushi Ogihara is an associate professor of Department of Health Sciences and Social Welfare, Faculty of Human Sciences at Waseda University, Japan. He has organized a research group about medical information. E-mail: aogi@waseda.jp. Corresponding author. 


\section{REFERENCES}

1. Japan's Ministry of Internal Affairs and Communications. (2011). A White Paper on Telecommunications. Retrieved February 2, 2012 from http://www.soumu.go.jp/johotsusintokei/whitepaper/ja/h23/pdf/n4010000.pdf

2. Internet World Stats. (2011). Top 20 countries with the highest number of internet users. Retrieved February 2, 2012 from http://www.internetworldstats.com/stats.htm

3. Japan Internet Medical Association. (2010). About JIMA. Retrieved May 1, 2011 from http://www.jima.or.jp/

4. Takahashi Y., Ohura Y., Ishizuki T., Okamoto S., Miki K., Naito M., Akamatsu R., Sugimori H., Yoshiike N., Shimbo T., Nakayama T. (2011). Internet use for health-related information via personal computers and cell phones in Japan: A cross-sectional population-based survey. Journal of Medical Internet Research, 13(4):e110.

5. Sydney Fox Susannah Jones. (2009). The Social Life of Health Information Americans' pursuit of health takes place within widening network of both online and offline sources. Retrieved February 2, 2012 from http://www.pewinternet.org/ /media//Files/Reports/2009/PIP_Health_2009.pdf

6. Tatsumi H., Mitani H., Haruki Y., Ogushi Y.. (2001). Internet Medical Usage in Japan: Current Situation and Issues. Journal of Medical Internet Research, 3(1):e12.

7. Utilization Review Certification Commission. (1990). Health Web Site Accreditation Guide, Version 3.0. Retrieved April 7, 2011 from http://www.urac.org/docs/programs/URACHW2.1factsheet.pdf

8. Jadad AR, Gagliardi A. (1998). Rating health information on the Internet: navigating to knowledge or to Babel?. The Journal of the American Medical Association, 279(8):611-614.

9. British Healthcare Internet Association. (1998). Quality standards for medical publishing on the Web. Retrieved May 1, 2011 from http://www.bhia.org/Provenance.htm

10. California Health Care Foundation. (2001). Proceed with Caution: A Report on the Quality of Health Information on the Internet Complete Study. Retrieved April 29, 2011 from http://www.chcf.org/ /media/MEDIA\%20LIBRARY\%20Files/PDF/P/PDF\%20ProceedWithCautionComp leteStudy.pdf

11. Risk A., Dzenowagis J. (2001). Review Of Internet Health Information Quality Initiatives. Journal of Medical Internet Research, 3(4):e28.

12. Eysenbach G. (1998). Towards quality management of medical information on the Internet: measurement, labeling, and filtering of information. British Medical Journal, 317:1496.

13. Coiera E. (1998). Information epidemics, economics, and immunity on the Internet. We still know so little about the effect of information on public health. British Medical Journal, 317:1469.

14. Eura A., Ogihara A., Mitani H.. (2009). A report on the quality of medical information on the Internet. Retrieved April 29, 2011 from http://www.jima.or.jp/kenkyuu/ronbun/eura_ronbun200903.pdf

15. Health On the Net Foundation. (1995). Medical professional. Retrieved May1, 2011 from http://www.hon.ch/

16. Ministry of Health, Labour and Welfare. (2002). Survey study on the control of reliability of internet use in medical and health fields. Retrieved December 21, 2011 from http://www.mhlw.go.jp/shingi/2002/12/s1206-6a.html

17. Robinson TN, Patrick KP, Eng TE et. al. (1998). An Evidenced-based Approach to Interactive Health Communication. The Journal of the American Medical Association, 280(14):1264-9.

18. The Japan Medical Association. (2002). Whole concept of Website of medical institutions. Retrieved March 7, 2012 from http://www.kochi.med.or.jp/hp_guide.pdf

19. Eysenbach G., Yihune G., Lampe K., Cross P., Brickley D. (2000). MedCERTAIN: quality management, certification and rating of health information on the NET, Annual Symposium Proceedings Archive, 230234.

20. Margaret A, Flanagin A., Chi-Lum B., White J., Andrews K., Kennett R., Catherine D. D., Robert A. M. (2000). Guideline for Medical and Health Information Sites on the Internet. The Journal of the American Medical Association, 283(12):1600-1606.

21. Kevin P. R.. (2004).What you should know about quality rating programs for health sites. Retrieved January 5, 2012 from http://www.medical-billing-company.com/medical-billing/medical-ratingswebsites.html 
22. Boyer C., Selby M., Scherre J-R., Appel R.D. (1995). The Health On the Net Code of Conduct for medical and health Websites. Computer in Biology and Medicine, 28(5), 603-610.

23. Wilson S. (1999). Impact of the internet on primary care staff in Glasgow. Journal of Medical Internet Research, 1(2):e7.

24. Communication of European Communities, Brussels. (2002). eEurope 2002: Quality Criteria for Health Related Websites-European Commission. Journal of Medical Internet Research, 4(3):e15.

25. Physician's review organization of Michigan. (2008). Accreditation. Retrieved January 2, 2012 from http://www.peerreviewmi.net/?i=urac

26. Japan Internet Medical Information. (1997). About Trust program of JIMA. Retrieved January 3, 2012 from http://www.jima.or.jp/trustguide/trustprogram.html

27. Utilization Review Certification Commission. (2008). URAC's Health Web Site a Health Content Vendor Accreditation Programs. Retrieved January 5, 2012 from https://www.urac.org/programs/prog_accred_HWS_po.aspx

28. Health On the Net Foundation. (1995). Certification Process. Retrieved January 3, 2012 from http://www.hon.ch/HONcode/Webmasters/StepByStep/StepByStep.html

29. Tatsumi H., Mitani H.. (2010). Investigative commission on the Internet about regulation of advertising. Retrieved December 21, 2011 from http://www.jima.or.jp/kenkyuu/ronbun/ronbun2010_3.html

30. Tatsumi H., Mitani H., Haruki Y., Ogushi Y.. (2001). Internet medical usage in Japan: Current situation and issues. Journal of Medical Internet Research, 3(1):e12.

31. Combination of Heterogeous. (2007). Combination of Heterogeneous Criteria for the Automatic Detection of Ethical Principles on Health web sites. Annual Symposium Proceedings Archive, 264-268.

32. Japan Internet Medical Association. (1998). e-Health Code of Ethics 2.0. Retrieved January 7, 2012 from http://www.jima.or.jp/ehealth_code/JIMAeHealth_code20(English).pdf 